\title{
A clinical review of phototherapy for psoriasis
}

\author{
Ping Zhang ${ }^{1,2}$ (D) $\cdot$ Mei X. Wu ${ }^{2}$
}

Received: 10 July 2017 / Accepted: 10 October 2017 / Published online: 24 October 2017

(C) The Author(s) 2017. This article is an open access publication

\begin{abstract}
Psoriasis is an autoimmune inflammatory skin disease. In the past several decades, phototherapy has been widely used to treat stable psoriatic lesions, including trunk, scalp, arms and legs, and partial nail psoriasis. A variety of light/ lasers with different mechanisms of action have been developed for psoriasis including ultraviolet B (UVB), psoralen ultraviolet A (PUVA), pulsed dye laser (PDL), photodynamic therapy (PDT), intense pulsed light (IPL), light-emitting diodes (LED), and so on. Because light/laser each has specific therapeutic and adverse effects, it is important to adequately choose the sources and parameters in management of psoriasis with different pathogenic sites, severities, and duration of the disorder. This review aims at providing most updated clinic information to physicians about how to select light/laser sources and individual therapeutic regimens. To date, UV light is primarily for stable plaque psoriasis and PDL for topical psoriatic lesions with small area, both of which are safe and effective. On the other hand, PUVA has better curative effects than UVB for managing refractory psoriasis plaques, if its side effects can be better controlled. PDL provides optimal outcomes on nail psoriasis compared with other lasers. Although the trails of low-level light/laser therapy
\end{abstract}

Ping Zhang

hautarzt2010@163.com

Mei X. Wu

MWU5@MGH.HARVARD.EDU

1 Department of Dermatology, Wuhan No.1 Hospital, Tongji Medical College, Huazhong University of Science and Technology, Wuhan, Hubei 430022, China

2 Wellman Center for Photomedicine, Massachusetts General Hospital, and Department of Dermatology, Harvard Medical School, Boston 02114, MA, USA
(LLLT) are still small, the near infrared (NIR) and visible red light with low energy show promise for treating psoriasis due to its strong penetration and encouraging photobiomodulation. IPL is rarely reported for psoriasis treatment, but PDT-IPL has been found to offer a moderate effect on nail psoriasis. In brief, various phototherapies have been used either in different combinations or as monotherapy. The modality has become a mainstay in the treatment of mild-to-moderate psoriasis without systemic adverse events in today's clinical practice.

Keywords Phototherapy $\cdot$ Psoriasis $\cdot$ Laser $\cdot$ Ultraviolet . Low-level light/laser

\section{Introduction}

Psoriasis is a chronic, recurrent, and immune-mediated inflammatory disease that affects $2-3 \%$ of the world population. It is associated with genetic predisposition, autoimmune disorders, psychiatry and psychological health, environmental factors (e.g., infection, stress, trauma), and so on. The pathogenesis is closely related to abnormal interactions among innate immunity, T cells, keratinocytes, etc. Immune cells in the patients release excess proinflammatory factors, leading to uncontrollable activation of congenital and acquired immune system, such as nuclear factor- $\mathrm{kB}$ (NF-kB) signaling pathway and differentiation of $\mathrm{T}$ helper (Th) cells toward Th1 and/or Th17 cells [1]. The complex pathogenesis results in tissue and organ damage over time, manifested by hyperproliferation, inflammation, and other clinical syndromes at the lesion sites. Therapeutic options for psoriasis can be divided into two aspects: systemic and topical treatments. The former involves immune inhibitors, like methotrexate, cyclosporine; retinoids (acitretin); immune modulators, such as glycyrrhizin, 
leflunomide [2]. Additionally, newly developed biological agents have been employed to treat moderate to severe psoriasis with body surface area (BSA) greater than $10 \%$ or psoriasis area and severity index (PASI) higher than 10 [3], including tumor necrosis factor $\alpha$ antagonists (etanercept, infliximab, etc.), alefacept, efalizumab, and ustekinumab [4]. As for topical treatment that is mainly for mild or moderate psoriasis, it includes ointments (e.g., calcipotriol, calcineurin inhibitors, tretinoin, glucocorticoid), medicated bath with diastase or herbal extracts, and phototherapy. Phototherapy is an effective, safe, and accessible treatment without incurring any systemic side effects, in contrast to biologic agents or other drugs, especially for stable plaque psoriasis. Moreover, phototherapy can be combined with biologic agents for the treatment of severe psoriasis [5].

Although phototherapy is convenient to use without severe adverse events, inadequate choice of laser/light types or parameters or unnecessary laser exposure could cause erythema, skin burning, photoaging, etc. It is therefore critical for clinicians to properly choose a right light source for a special type of psoriasis. We review the current literatures and focus on recent developments in psoriasis phototherapy by comparing curative effects between commonly used therapies and some new methodologies. We also update information with respect to their mechanisms of action in an attempt to provide some clinical guidance for psoriasis phototherapy.

\section{Phototherapy for psoriasis}

Many types of phototherapy have been developed and used for the treatment of psoriasis over the last few decades as summarized in Table 1. Among them, broadband ultraviolet B light (BB-UVB, 290-320 nm) was first developed, but was later replaced by narrowband ultraviolet B (NB-UVB, $311 \mathrm{~nm}$ ) as the latter is more effective than the former. The excimer laser/lamp of $308 \mathrm{~nm}$ was next invented in 1997 and used as a monochromatic UVB source for psoriasis treatment. The advantage of using excimer is its targeting ability that can spare unaffected skin while providing high doses to the skin involved. Studies found that the $308-\mathrm{nm}$ excimer lamp is as effective in clearance of psoriasis as the excimer laser [6]. Both NB-UVB and excimer laser are currently used as the first-line therapy for stable plaque psoriasis. A conventional photochemotherapy using UV is called psoralen ultraviolet A (PUVA), which combines a photosensitizing drug and ultraviolet radiation. PUVA can be either systemic (oral, injection) or bath/cream-PUVA, both of which have been used to treat plaque psoriasis in stationary phase [7]. Some researchers selected PUVB to treat plaque psoriasis and found that PUVB had the similar curative and side effects as PUVA [8]. Apart from UV light, the flash lamp pumped pulsed dye laser (PDL) has a wavelength of $585-595 \mathrm{~nm}$, which targets the chromophore hemoglobin and can selectively damage vessels, so PDL is the preferred laser for congenital and acquired vascular

Table 1 Summary of phototherapeutics for psoriasis

\begin{tabular}{|c|c|c|c|}
\hline Classification of light source & Sub-light source & Wavelengths & Indications \\
\hline \multicolumn{4}{|l|}{ First-line therapy } \\
\hline \multirow[t]{2}{*}{ UVB } & NB-UVB & $311 \mathrm{~nm}$ & Stable plaque psoriasis, $>10 \%$ body surface \\
\hline & excimer laser/lamp & $308 \mathrm{~nm}$ & Topical plaque psoriasis, non-pustular palmoplantar psoriasis \\
\hline \multicolumn{4}{|l|}{ Second-line therapy } \\
\hline \multirow[t]{2}{*}{ PUVA } & bath/cream-PUVA & $320-400 \mathrm{~nm}$ & Refractory psoriatic plaques, palmoplantar pustular psoriasis \\
\hline & Oral-PUVA & $320-400 \mathrm{~nm}$ & Stable plaque psoriasis, palmoplantar psoriasis \\
\hline PDL & & $585-595 \mathrm{~nm}$ & Nail psoriasis \\
\hline \multicolumn{4}{|l|}{ Third-line therapy } \\
\hline PDL & & $585-595 \mathrm{~nm}$ & Topical plaque psoriasis \\
\hline \multirow[t]{3}{*}{ PDT } & LED & & chronic plaque psoriasis, Nail psoriasis \\
\hline & $\mathrm{He}-\mathrm{Ne}$ & $632.8 \mathrm{~nm}$ & \\
\hline & IPL & $555-950 \mathrm{~nm}$ & \\
\hline Red light & & $620-770 \mathrm{~nm}$ & Plaque psoriasis \\
\hline Blue light & & $400-480 \mathrm{~nm}$ & Plaque psoriasis \\
\hline NIR & & $830 \mathrm{~nm}, 810 \mathrm{~nm}$ & Plaque psoriasis \\
\hline Excimer & & $308 \mathrm{~nm}$ & Nail psoriasis \\
\hline IPL & & $550-950 \mathrm{~nm}$ & Plaque psoriasis \\
\hline PUVB & & $290-320 \mathrm{~nm}$ & Stable plaque psoriasis \\
\hline BB-UVB & & $290-320 \mathrm{~nm}$ & Stable plaque psoriasis \\
\hline Sunbath & & $400-760 \mathrm{~nm}$ & Chronic plaque psoriasis \\
\hline
\end{tabular}


lesions [9]. PDL was first used to treat psoriasis in 1992 by Hacker and Rasmussen [10]. PUVA and PDL become the second-line therapy for plaque psoriasis, with preference of PUVA to refractory psoriatic plaques and PDL to nail psoriasis (Table 1). Finally, low-level light/laser therapy (LLLT) has been widely applied in dermatology. It has been recently considered to be effective for psoriasis treatment. A preliminary study investigated efficacy of combination of $830 \mathrm{~nm}$ (near infrared) and $630 \mathrm{~nm}$ (visible red light) emitted by light emitting diode (LED) to treat recalcitrant psoriasis [11]. Because of its ability of stronger penetration and potential photobiomodulation, LLLT has a promising expectation. In the future, other types of laser and light sources should be explored for the treatment of psoriasis.

\section{Clinical effects of UV light and the regulatory pathways}

UV phototherapy is a popular treatment for psoriasis. Specifically, UVB therapy is generally for lesions covering at least $10 \%$ of body surface. In some specific cases, e.g., palmoplantar psoriasis that covers much less body surface can be also treated with UV light. In comparison with BBUVB, NB-UVB clears psoriatic lesions faster and produces longer remissions with a good safety profile. Typical regimens of NB-UVB involve dosing three times per week for at least 3 months [12], and an appropriate initiating dose is usually $50 \%$ of the minimal erythema dose (MED) and/or simultaneously determined according to Fitzpatrick skin type. A randomized double-blind comparison of high dose and low dose of NB-UVB radiations in psoriasis patients has revealed that both regimens have comparable clearance rates, but the highdose radiation prolongs remission with a fewer sessions of treatment [13]. Moreover, NB-UVB can be combined with other topical therapies, such as emollients, calcipotriene, and coal tar, to significantly improve its efficacy $[14,15]$. It can also be combined with systemic agents in moderate-to-severe psoriasis patients, such as methotrexate and mycophenolate mofetil [16]. Acitretin is a retinoid; it can regulate the differentiation and proliferation of epidermal cells, and it can be used in the treatment of severe psoriasis alone or safely combined with phototherapy. A combination of oral retinoids and NB-UVB reduced treatment time, recovery frequency, and dose-limiting side effects [6]. Excimer laser/lamp with limited spot size, which emits a light of $308 \mathrm{~nm}$ via xenon-chloride gases, is more applicable to psoriasis lesions at a size of less than $10 \%$ body surface, for instance, in palms, soles, elbows, or knees. The excimer laser was found to be as efficacious as topical PUVA in non-pustular palmoplantar psoriasis [17].

Psoriasis responds to UV radiation favorably, but the underlying mechanisms are not well understood. It is known that
UVB induces apoptosis of pathogenic $\mathrm{T}$ cells and keratinocytes, inducing local and systemic immunosuppression. Accumulating evidence suggested that Th17 and T regulatory (Treg) cells play critical roles in the pathogenesis of psoriasis. Th17 pathway was downregulated by NB-UVB in psoriatic epidermis [18], as suggested by significant decreases of IL-17A, TNF- $\alpha$, and IL- 6 mRNA in peripheral blood mononuclear cells (PBMCs) in psoriasis patients following NB-UVB treatment [19]. In addition, IL-17F polymorphism might also affect the response to NB-UVB phototherapy [20]. Strikingly, downregulation of Th17 pathway was not accompanied with enhanced Th1 responses. Instead, UV treatment triggered ubiquitination and downregulation of the type I interferon (IFN) receptor chain IFNAR1 and thereby suppressed IFN signaling and the expression of related cytokines [21]. In this regard, Treg dysfunction and down-regulation are associated with psoriasis. Therefore, NB-UVB and PUVA increase Treg cells and restore Treg function via the upregulation of FOXP3 in Treg cells, alleviating psoriasis [22]. Another possibility is that reduced plasmin (a potent inflammatory cell activator) levels may be ascribed to the cumulative dose of NB-UVB, which also contributed to the therapeutic effect of NB-UVB on psoriasis [23].

PUVA is the gold standard of photochemotherapy modalities mainly for topical psoriatic plaques. Psoralen acts by intercalation of cellular DNA and forms monoadducts that induce apoptosis upon exposure to UVA. PUVA-induced apoptosis in HaCaT keratinocytes was thought to be induced by Homo sapiens microRNA-4516-mediated downregulation of STAT3/CDK6/UBE2N [24]. Studies have shown a better efficacy of PUVA, compared to UVB therapy on palmoplantar pustular psoriasis which is characterized by repeated eruptions of sterile pustules on the palms and soles, but it is without any differences between bath and oral-PUVA [25]. However, its application is limited owing to topical stimulation reaction, weak percutaneous permeability, gastrointestinal symptoms associated with systemic psoralens, and concerns over their long-term carcinogenic risk [26]. The efficacy and safety of topical PUVA was improved by liposomal nanocarriers of psoralen in imiquimod-induced psoriatic plaque model because the nanoparticle-packaged psoralen enhanced skin penetration of the drug and reduced its adverse effects on burning, blister, and pigmentation [27]. However, its clinical benefits remain to be determined.

Both PUVA and NB-UVB are effective therapies in psoriasis. However, considering the potential risks, dermatologists prefer NB-UVB as the first-line phototherapy (Table 1). If the systemic inflammation is under control in psoriasis pustular or erythrodermic psoriasis, NB-UVB can be also used to shorten the treatment time. If NB-UVB for the treatment of refractory plaque psoriasis in adults is invalid or does not make any progress, PUVA either alone or in combination with topical medications can be an alternative. UVB and PUVA can also 
be employed in pediatric psoriasis if children are mentally and psychologically able to tolerate the procedure and accept eye protection. Bath and cream PUVA are preferred over oral PUVA in pediatric psoriasis, but should be restricted to those aged over 10 or 16 years, respectively [28].

\section{Pulsed dye laser treatment and its mechanism}

PDL is the preferred therapy for most superficial cutaneous vascular lesions. In recent years, it has been used in some clinical researches to treat non-vascular indications, such as psoriasis, acne vulgaris, papulopustular rosacea, hypertrophic scar, and so on [29]. Erceg et al. [30] have reviewed the efficacy of PDL for inflammatory skin disease and concluded that PDL is an effective and safe method to treat localized plaque psoriasis. In accordance with this, a prospective randomized controlled study was performed to compare the efficacy of PDL with UVB-TL01 in plaque psoriasis. PDL parameters used were $585 \mathrm{~nm}$, a pulse duration of $0.45 \mathrm{~ms}$, and a spot size of $7 \mathrm{~mm}$ with spot overlapping about $20 \%$ at fluencies $5.5-6.5 \mathrm{~J} / \mathrm{cm}^{2}$ for a total of four treatments at an interval of 3 weeks between two treatments. Improvement of psoriasis lesions was noted at the 13th week, yet with no significant differences between PDL and UVB [31]. A within-patient controlled prospective trial of treatment of localized plaque psoriasis with excimer (twice weekly) and PDL (every 4 weeks) showed that excimer and PDL were useful treatments for plaque psoriasis with long-term remission, but psoriasis severity index (PSI) improvement was significantly greater in excimer than PDL [32]. Studies of PDL in psoriasis also reported low clearance rate, which could be improved by applying keratolytics with salicylic acid on psoriatic plaques before PDL treatment [33].

In spite of its effectiveness in clearing psoriasis plaques, the mechanism underlying PDL therapy has not yet been elucidated. It has been shown that the levels of VEGFR-2, 3, and Eselectin protein were reduced in lesions after PDL treatment, followed by downregulation of TNF- $\alpha$ and IL-23p19 [34]. It was speculated that PDL mainly acted on the capillaries in the upper dermis. PDL-induced selective photothermolysis of hemoglobin in vessels was one of the mechanisms of the clearance of psoriatic lesions. Apart from photothermolysis, PDL also reduced activated and memory effector Th cells in the dermis and cytotoxic $\mathrm{T}$ cells in the epidermis in plaque psoriasis [35], concurrent with induction of cytokine expression and collagen formation [36]. Studies about PDL treatment of hypertrophic scar have shown that PDL is strongly absorbed by hemoglobin, leading to coagulation necrosis in vessels, hypoperfusion, and local hypoxia [37]. Moreover, PDL could also play a role in limiting the production of transforming growth factor and platelet-derived growth factor; it can stimulate matrix metalloproteinases and IL- 6 for matrix degradation $[38,39]$. However, how these gene transcriptional activities are triggered by PDL remains largely unknown.

\section{Low-level light/laser therapy for psoriasis and the mechanism of action}

In recent years, LLLT has been widely applied in dermatology. LLL is also called "cold laser," which involves ultraviolet, visible, and near infrared with much lower energy densities than those lasers used for ablation, cutting, and thermally coagulating tissues. Light sources of LLLT include LED, helium-neon (He-Ne, $632.8 \mathrm{~nm})$, and gallium arsenide (GaAs) laser. LED is the complex semiconductor that converts electrical current into incoherent narrow spectrum light. LED or lasers at a wavelength ranging from 600 to $1070 \mathrm{~nm}$ have been widely applied to LLLT. Although longer wavelengths penetrate deeper, lasers at $700-770 \mathrm{~nm}$ have been found to limit biochemical activity [40, 41]. Blue light (400-480 nm) can reduce the proliferative activity of keratinocytes, modulate $\mathrm{T}$ cell immune responses, and safely improve plaque psoriasis [42]. It is thus propitious to treat chronic hyperplastic and inflammatory dermatosis, such as psoriasis and atopic dermatitis. A prospective randomized study by comparing the efficacy of blue light (420 and $453 \mathrm{~nm}$, LED) in treatment of psoriasis vulgaris once daily for 4 weeks showed significant improvement in either wavelength [43]. Red light (620 $770 \mathrm{~nm}$ ) is able to deeply penetrate skin to about $6 \mathrm{~mm}$ [44], stimulate mitochondrial activity, and modulate cytokine release from macrophages to reduce topical inflammation [45]. When patients with plaque psoriasis were treated sequentially with LED delivering continuous 830 and $633 \mathrm{~nm}$ in two 20min sessions for 4 or 5 weeks, $60-100 \%$ of clearance rates were achieved without any significant side effects [11].

LLL is characterized by its ability to induce photobiological processes in cells. For instance, laser at $810 \mathrm{~nm}$ was shown to activate NF-kB in primary murine embryonic fibroblasts cells [46]. In contrast, a combination of curcumin (antiproliferation) with LED blue light, along with red light radiation in psoriasis, inhibited NF- $\mathrm{KB}$ activity, activated caspase$8 / 9$, and downregulated the phosphorylation level of Akt and ERK [47]. A growing number of investigations have demonstrated that LLL can improve mitochondrial function under stress by increasing ATP synthesis, reactive oxygen species (ROS) generation, and cell redox activity [40, 48]. The beneficial functions of LLLT rely on its ability to activate cytochrome $\mathrm{c}$ oxidase at the mitochondrial respiratory chain. Cytochrome c oxidase has strong absorption of light at wavelengths ranging from 670 to $830 \mathrm{~nm}$ [49]. Recent studies also showed that LLLT increased mitochondrial biogenesis in megakaryocytes, facilitating platelet biogenesis both in vivo and in vitro in preclinical studies [50]. Finally, laser irradiation at green, red, or infrared wavelength with special parameters 
can change gene expression and release of various mediators in human and animal cells. [51]. LLLT has been also commonly used in a variety of conditions for acceleration of healing and relief of pain and inflammation, etc. [52, 53]. Its advantages of non-invasion, few side effects, and measurable benefits merit to be explored in the treatment of psoriasis.

\section{Others}

Photodynamic therapy (PDT) using 5-aminolevulinic acid (ALA) as photosensitizer is effective for superficial skin tumors partially because of its selective cytotoxic effect. The light sources of PDT include LED, He-Ne, IPL, and other visible lights. In recent years, PDT was employed to treat some inflammatory dermatoses (e.g., severe acne, rosacea, and psoriasis). PDT stimulated diverse immune cells to produce various cytokines, such as IL- $1 \beta$, IL-2, and TNF- $\alpha$. And fibroblasts secreted MMP- 1 and 3 in response to PDT $[54,55]$. The benefit of PDT to inflammatory dermatoses is probably ascribed to its suppression of TGF- $\beta 1$ expression, while increasing IL-10 production, which was demonstrated in cultured fibroblasts after ALA-IPL-PDT [56]. However, the study of PDT-methyl aminolevulinate suggested a low proportion of psoriasis patients with complete remission, only six out of 17 [57]. Topical ALA-PDT was inadequate for chronic plaque psoriasis because of variability in clinical responses and severe pain. Single IPL has been applied to vascular skin disease, such as facial telangiectasias and port-wine stains. At present, IPL has been widely used to photorejuvenation as noninvasive therapy either alone or in combination with the photosensitizer [58]. A fewer literatures reported that IPL with 550-nm filter was effective to plaque psoriasis [59]. In this regard, sunlight contains mainly UV and visible and infrared light, and UVB from the sun works the same way as UVB in phototherapy. Thus, multiple and short exposures to sunlight are recommended in psoriasis patients if they are tolerant to sunlight in the basis of clinical studies of phototherapy. Yet, natural sunbath is so unbound, rendering patients to the risks of photosensitivity and sunburn increase, and thus it should be carefully monitored. The patients should apply broad-spectrum sunscreen to all areas of unaffected skin and wear sunglasses during sunbath.

\section{Phototherapy for nail psoriasis}

Up to $50 \%$ of psoriasis patients have nail changes. Patients with psoriatic arthritis have an 80 to $90 \%$ lifetime incidence of developing nail psoriasis [60]. The manifestations of nail psoriasis include nail plate pitting, onycholysis, nail bed discoloration, sub-ungual hyperkeratosis, etc. Psoriatic nails tend to be progressive if left untreated and can significantly impair patient's quality of life. The management of nail psoriasis includes patient education, topical ointments, and systemic therapy (e.g., methotrexate, acitretin, cyclosporine A, biologic agents). Phototherapy is useful when few nails are involved. In 2009, PDL was firstly used to treat nail psoriasis in which 61 nails were treated with PDT (MAL + PDL) and 60 nails treated with PDL alone. The nails treated with PDL had $33 \%$ improvement after 3 months and 58\% improvement after 6 months in the basis of the nail psoriasis severity index (NAPSI) score, but it was without no statistical differences between PDT and PDL [61]. Other studies investigated PDL with different pulse durations and energy densities were also effective and well-tolerated to treat nail psoriasis [62]. A single-blinded comparison study of excimer laser and PDL, in which patients' right hand nails were treated with excimer laser for twice weekly and the left hand nails with PDL for once every 4 weeks, showed that NAPSI improvement was greater in PDL than excimer group after 12 weeks [63]. A followed-up study in which finger and toe nails of 20 patients with psoriasis were treated by IPL at $550 \mathrm{~nm}$ exhibited improvement in the nail bed $(71.2 \%)$ and nail matrix $(32.2 \%)$ after a mean of $8.63 \pm 3.6$ treatment sessions [59]. However, the penetration of UVA and UVB was extremely poor in the human fingernails and the nail plates completely blocked UVB. The mean penetration of UVA was $1.65 \%$ and thus therapeutic effect of UV for nail psoriasis might be poor ${ }^{[} 64$.

\section{Potential risks}

The short-term side effects of phototherapy are generally mild and self-limiting, such as erythema, edema, pruritus, pain, purpura, transient petechiae, blister, and crusting, which occur during treatment or within the first $24 \mathrm{~h}$ after the treatment. The main long-term side effects include pigmentary disorder, photoaging, cataracts, and carcinogenesis. Photodermatitis usually occurs in UV radiation as UV-induced DNA damage or mutations result in activation of oncogenes or silencing of tumor-suppressor genes, which are closely related to the pathogenesis of skin squamous-cell carcinoma [65]. Furthermore, UV radiation was associated with melanoma. The children younger than 12 years of age who sustained frequent episodes of sunburn or UV exposure had a 3-4-fold increased risk of melanoma [66]. To reduce the complications and side effects, physicians should undergo standard training and exclude the patients who are intolerant to light and display obvious phototoxic or photosensitive reaction under radiation and who are using drugs (e.g., sulfonamides, fluoroquinolones, coal tar, tazarotene) that can impose a risk of photosensitivity. Patients using these drugs should talk with a doctor before 
treatment. In addition, pregnant women and those who are suffering from cardiac/cerebrovascular diseases, preexisting or manifest skin malignancy cannot receive phototherapy.

\section{Summation and future directions}

Psoriasis is an inflammatory skin disease, involving the complex interaction network among which a variety of cells respond to light radiation differently. The outcome of phototherapy depends on a delicate balance between beneficial and detrimental effects of a specific laser. In comparison with other laser modalities, PUVA and UVB have the advantages of large radiation sizes, low price, and efficacy and safety that have been intensively demonstrated. In addition, PUVA has better effects than UVB on refractory psoriasis plaque and palmoplantar pustular psoriasis, but its side effects limit its broad application (Table 1). PDL provides optimal outcomes on nail psoriasis compared with other lasers. The trails of LLLT are still limited, but the NIR and visible red light with low energy show prospects for treating psoriasis due to its strong penetration and encouraging photomodulation. IPL is rarely reported for the treatment of psoriasis, but PDT-IPL has been found to offer a moderate effect on nail psoriasis.

Light spectra have different depths of penetration in skin, which can be applied to different target cells or tissues to obtain certain effects. In comparison with sunlight, if the curative effects of a light source, especially non-monochromatic light, are not as effective as sunlight or comparable, it does not have high clinical values. Apparently, artificial light has the advantage that can deliver high-dose radiation to the target in a short time, which may be also one of the therapeutic mechanisms. It is thus possible that combination of various monochromatic lights acting on different targets can be a groundbreaking way to improve outcomes of phototherapy in the future.

Open Access This article is distributed under the terms of the Creative Commons Attribution 4.0 International License (http:// creativecommons.org/licenses/by/4.0/), which permits unrestricted use, distribution, and reproduction in any medium, provided you give appropriate credit to the original author(s) and the source, provide a link to the Creative Commons license, and indicate if changes were made.

\section{References}

1. Greb JE, Goldminz AM, Elder JT, Lebwohl MG, Gladman DD, JJ W, Mehta NN, Finlay AY, Gottlieb AB (2016) Psoriasis. Nat Rev Dis Primers 2:16082

2. Goldenberg G, Lanoue J, Dong J (2016) New oral therapies for psoriasis: a comprehensive review. J Clin Aesthet Dermatol 9(8): $25-28$
3. Menter A, Korman NJ, Elmets CA, Feldman SR, Gelfand JM, Gordon KB, Gottlieb AB, Koo JY, Lebwohl M, Lim HW, Van Voorhees AS, Beutner KR, Bhushan R (2009) Guidelines of care for the management of psoriasis and psoriatic arthritis: section 4 . Guidelines of care for the management and treatment of psoriasis with traditional systemic agents. J Am AcadDermatol 61(3): 451-485

4. Laws PM, Warren RB (2011) Ustekinumab for the treatment of psoriasis. Expert Rev Clin Immunol 7(2):155-164

5. Calzavara-Pinton PG, Sala R, Arisi M, Rossi MT, Venturini M, Ortel B (2013) Synergism between narrowband ultraviolet B phototherapy and etanercept for the treatment of plaque-type psoriasis. Br J Dermatol 169(1):130-136

6. Mehta D, Lim HW (2016) Ultraviolet B phototherapy for psoriasis: review of practical guidelines. Am J ClinDermatol 17(2):125-133

7. Stern RS (2007) Psoralen and ultraviolet a light therapy for psoriasis. N Engl J Med 357(7):682-690

8. Ahmed Asim S, Ahmed S, Us-Sehar N (2013) Psoralen-ultraviolet a treatment with psoralen-ultraviolet B therapy in the treatment of psoriasis. Pak J Med Sci 29(3):758-761

9. Astner S, Anderson RR (2005) Treating vascular lesions. Dermatol Ther 18:267-281

10. Hacker SM, Rasmussen JE (1992) The effect of flash lamp-pulsed dye laser on psoriasis. Arch Dermatol 128:853-855

11. Ablon G (2010) Combination 830-nm and 633-nm light-emitting diode phototherapy shows promise in the treatment of recalcitrant psoriasis: preliminary findings. Photomed Laser Surg 28(1):141-146

12. Lapolla W, Yentzer BA, Bagel J, Halvorson CR, Feldman SR (2011) A review of phototherapy protocols for psoriasis treatment. J Am Acad Dermatol 64(5):936-949

13. Kleinpenning MM, Smits T, Boezeman J, van de Kerkhof PC, Evers AW, Gerritsen MJ (2009) Narrowband ultraviolet B therapy in psoriasis: randomized double-blind comparison of high-dose and low-dose irradiation regimens. Br J Dermatol 161:1351-1356

14. Mrowietz U, Kragballe K, Reich K, Spuls P, Griffiths CE, Nast A, Franke J, Antoniou C, Arenberger P, Balieva F, Bylaite M, Correia O, Daudén E, Gisondi P, Iversen L, Kemény L, Lahfa M, Nijsten T, Rantanen T, Reich A, Rosenbach T, Segaert S, Smith C, Talme T, Volc-Platzer B, Yawalkar N (2011) Definition of treatment goals for moderate to severe psoriasis: a European consensus. Arch Dermatol Res 303:1-10

15. Samarasekera E, Sawyer L, Parnham J, Smith CH (2012) Guideline development group assessment and management of psoriasis: summary of NICE guidance. BMJ 345:e6712

16. Menter A, Gottlieb A, Feldman SR, Van Voorhees AS, Leonardi CL, Gordon KB, Lebwohl M, Koo JY, Elmets CA, Korman NJ, Beutner KR, Bhushan R (2008) Guidelines of care for the management of psoriasis and psoriatic arthritis: section 1. Overview of psoriasis and guidelines of care for the treatment of psoriasis with biologics. J Am AcadDermatol 58(5):826-850

17. Neumann NJ, Mahnke N, Korpusik D, Stege H, Ruzicka T (2006) Treatment of palmoplantar psoriasis with monochromatic excimer light (308-nm) versus cream PUVA. Acta DermVenereol 86:22-24

18. Rácz E, Prens EP, Kurek D, Kant M, de Ridder D, Mourits S, Baerveldt EM, Ozgur Z, van IJcken WF, Laman JD, Staal FJ, der $v$, Fits L (2011) Effective treatment of psoriasis with narrowband UVB phototherapy is linked to suppression of the IFN and Th17 pathways. J Ibvest Dermatol 131(7):1547-1558

19. Batycka-Baran A, Besgen P, Wolf R, Szepietowski JC, Prinz JC (2016) The effect of phototherapy on systemic inflammatory process in patients with plaque psoriasis. J Photo chem Photo biol B 161:396-401

20. Białecka M, Ostasz R, Kurzawski M, Klimowicz A, Fabiańczyk H, Bojko P, Dziedziejko V, Safranow K, Machoy-Mokrzyńska A, Droździk M (2016) IL17A and IL17F gene polymorphism 
association with psoriasis risk and response to treatment in a polish population. Dermatology 232(5):592-596

21. Gui J, Gober M, Yang X, Katlinski KV, Marshall CM, Sharma M, Werth VP, Baker DP, Rui H, Seykora JT, Fuchs SY (2016) Therapeutic elimination of the type 1 interferon receptor for treating psoriatic skin inflammation. J Invest Dermatol 136(10):1990-2002

22. Zhang D, Chen Y, Chen L, Yang R, Wang L, Liu W, Zhai Z, Shen Z (2016) Ultraviolet irradiation promotes FOXP3 transcription via p53 in psoriasis. Exp Dermatol 25(7):513-518

23. Metwally D, Sayed K, Abdel Hay R, Rashed L (2015) Reduction in tissue plasmin: a new mechanism of action of narrowband ultraviolet B in psoriasis. Clin Exp Dermatol 40(4):416-420

24. Chowdhari S, Saini N (2014) Hsa-miR-4516 mediated downregulation of STAT3/CDK6/ UBE2N plays a role in PUVA induced apoptosis in keratinocytes. J Cell Physiol 229(11):1630-1638

25. Sevrain M, Richard MA, Barnetche T, Rouzaud M, Villani AP, Paul C, Beylot-Barry M, Jullien D, Aractingi S, Aubin F, Joly P, Le Maitre M, Cantagrel A, Ortonne JP, Misery L (2014) Treatment for palmoplantar pustular psoriasis: systematic literature review, evidence-based recommendations and expert opinion. J Eur Acad Dermatol Venereol 28(Suppl 5):13-16

26. Weatherhead SC, Farr PM, Reynolds NJ (2013) Spectral effects of UV on psoriasis. PhotochemPhotobiol Sci 12(1):47-53

27. Doppalapudi S, Jain A, Chopra DK, Khan W (2017) Psoralen loaded liposomal nanocarriers for improved skin penetration and efficacy of topical PUVA in psoriasis. Eur J Pharm Sci 96:515-529

28. Höölzle E (2011) Phototherapy and photochemotherapy in childhood psoriasis. Expert Rev Dermatol 6:4

29. Karsai S, Roos S, Hammes S, Raulin C (2007) Pulsed dye laser: what's new in non-vascular lesions? J Eur Acad Dermatol Venereol 21(7):877-890

30. Erceg A, de Jong EM, van de Kerkhof PC, Seyger MM (2013) The efficacy of pulsed dye laser treatment for inflammatory skin diseases: a systematic review. J Am Acad Dermatol 69(4):609-615

31. De Leeuw J, Van Lingen RG, Both H, Tank B, Nijsten T, Martino Neumann HA (2009) A comparative study on the efficacy of treatment with $585 \mathrm{~nm}$ pulsed dye laser and ultraviolet B-TL01 in plaque type psoriasis. Dermatol Surg 35(1):80-91

32. Taibjee SM, Cheung ST, Laube S, Lanigan SW (2005) Controlled study of excimer and pulsed dye lasers in the treatment of psoriasis. Br J Dermatol 153:960-966

33. Ilknur T, Akarsu S, Aktan S, Ozkan S (2006) Comparison of the effects of pulsed dye laser, pulsed dye laser + salicylic acid, and clobetasole propionate + salicylic acid on psoriatic plaques. Dermatol Surg 32(1):49-55

34. Rácz E, de Leeuw J, Baerveldt EM, Kant M, Neumann HA, van der Fits L, Prens EP (2010) Cellular and molecular effects of pulsed dye laser and local narrow-band UVB therapy in psoriasis. Lasers Surg Med 42(3):201-210

35. Bovenschen HJ, Erceg A, Van Vlijmen-Willems I, Van De Kerkhof PC, Seyger MM (2007) Pulsed dye laser versus treatment with calcipotriol/betamethasone dipropionate for localized refractory plaque psoriasis: effects on T-cell infiltration, epidermal proliferation and keratinization. J Dermatolog Treat 18(1):32-39

36. Liu A, Moy RL, Ross EV, Hamzavi I, Ozog DM (2012) Pulsed dye laser and pulsed dye laser-mediated photodynamic therapy in the treatment of dermatologic disorders. Dermatol Surg 38(3):351-366

37. Bouzari N, Davis SC, Nouri K (2007) Laser treatment of keloids and hypertrophic scars. Int J Dermatol 46(1):80-88

38. Kuo YR, Wu WS, Jeng SF, Wang FS, Huang HC, Lin CZ, Yang KD (2005) Suppressed TGF-beta1 expression is correlated with up-regulation of matrix metalloproteinase-13 in keloid regression after flashlamp pulsed-dye laser treatment. Lasers Surg Med 36(1):38-42

39. Nouri K, Elsaie ML, Vejjabhinanta V, Stevens M, Patel SS, Caperton C, Elgart G (2010) Comparison of the effects of short- and long-pulse durations when using a 585-nm pulsed dye laser in the treatment of new surgical scars. Lasers Med Sci 25(1):121-126

40. Chung H, Dai T, Sharma SK, Huang YY, Carroll JD, Hamblin MR (2012) The nuts and bolts of low-level laser (light) therapy. Ann Biomed Eng 40(2):516-533

41. Avci P, Gupta A, Sadasivam M, Vecchio D, Pam Z, Pam N, Hamblin MR (2013) Low-level laser (light) therapy (LLLT)in skin: stimulating, healing, restoring. SeminCutan Med Surg 32(1):41-52

42. Pfaff S, Liebmann J, Born M, Merk HF, von Felbert V (2015) Prospective randomized long-term study on the efficacy and safety of UV-free blue light for treating mild psoriasis vulgaris. Dermatology 231(1):24-34

43. Weinstabl A, Hoff-Lesch S, Merk HF, von Felbert V (2011) Prospective randomized study on the efficacy of blue light in the treatment of psoriasis vulgaris. Dermatol 223:251-259

44. Niu T, Tian Y, Ren Q, Wei L, Li X, Cai Q (2014) Red light interferes in UVA-induced photoaging of human skin fibroblast cells. Photochem Photobiol 90(6):1349-1358

45. Kwon HH, Lee JB, Yoon JY, Park SY, Ryu HH, Park BM, Kim YJ, Suh DH (2013) The clinical and histological effect of home-use, combination blue-red LED phototherapy for mild-to-moderate acne vulgaris in Korean patients: a double-blind, randomized controlled trial. Br J Dermatol 168:1088-1094

46. Chen AC, Arany PR, Huang YY, Tomkinson EM, Sharma SK, Kharkwal GB, Saleem T, Mooney D, Yull FE, Blackwell TS, Hamblin MR (2011) Low level laser therapy activates NF-jB via generation of reactive oxygen species in mouse embryonic fibroblasts. PLoS One 6(7):e22453

47. Niu T, Tian Y, Cai Q, Ren Q, Wei L (2015) Red light combined with blue light irradiation regulates proliferation and apoptosis in skin keratinocytes in combination with low concentrations of curcumin. PLoS One 10(9):e0138754

48. Huang YY, Sharma SK, Carroll J, Hamblin MR (2011) Biphasic dose response in low level light therapy an update. Dose Response 9(4):602-618

49. Wong-Riley MT, Liang HL, Eells JT, Chance B, Henry MM, Buchmann E, Kane M, Whelan HT (2005) Photobiomodulation directly benefits primary neurons functionally inactivated by toxins: role of cytochrome c oxidase. J Biol Chem 280(6): 4761-4771

50. Zhang Q, Dong T, Li P, Wu MX (2016) Noninvasive low-level laser therapy for thrombocytopenia. Sci Transl Med 8(349):349 ra101

51. Peplow PV, Chung TY, Ryan B, Baxter GD (2011) Laser photobiomodulation of gene expression and release of growth factors and cytokines from cells in culture: a review of human and animal studies. Photomed Laser Surg 29(5):285-304

52. Dong T, Zhang Q, Hamblin MR, MX W (2015) Low-level light in combination with metabolic modulators for effective therapy of injured brain. J Cereb Blood Flow Metab 35(9):1435-1444

53. Zhang Q, Zhou C, Hamblin MR, MX W (2014) Low-level laser therapy effectively prevents secondary brain injury induced by immediate early responsive gene X-1 deficiency. J Cereb Blood Flow Metab 34(8):1391-1401

54. Keyal U, Bhatta AK, Wang XL (2016) Photodynamic therapy for the treatment of different severity of acne: a systematic review. Photodiagn Photodyn Ther 14:191-199

55. Kim M, Jung HY, Park HJ (2015) Topical PDT in the treatment of benign skin diseases: principles and new applications. Int J Mol Sci 16(10):23259-23278

56. Byun JY, Lee GY, Choi HY, Myung KB, Choi YW (2011) The expressions of TGF- $\beta(1)$ and IL-10 in cultured fibroblasts after ALA-IPL photodynamic treatment. Ann Dermatol 23(1):19-22

57. Calzavara-Pinton PG, Rossi MT, Aronson E, Sala R (2013) Italian group for photodynamic therapy. A retrospective analysis of real life practice of off label photodynamic therapy using methylaminolevulinate MAL-PDT in 20 Italian dermatology 
departments. Part 1: inflammatory and aesthetic indications. Photochem Photobiol Sci 12(1):148-157

58. Le Pillouer-Prost A, Cartier H (2016) Photodynamic photorejuvenation: a review. Dermatol Surg 42(1):21-30

59. Tawfik AA (2014) Novel treatment of nail psoriasis using the intense pulsed light: a one-year follow-up study. Dermatol Surg 40(7):763-768

60. Schons KR, Beber AA, Beck Mde O, Monticielo OA (2015) Nail involvement in adult patients with plaque-type psoriasis: prevalence and clinical features. An Bras Dermatol 90(3):314-319

61. Fernández-Guarino M, Harto A, Sánchez-Ronco M, GarcíaMorales I, Jaén P (2009) Pulsed dye laser vs. photodynamic therapy in the treatment of refractory nail psoriasis: a comparative pilot study. J Eur Acad Dermatol Venereol 23:891-895

62. Treewittayapoom C, Singvahanont P, Chanprapaph K, Haneke E (2012) The effect of different pulse durations in the treatment of nail psoriasis with 595-nm pulsed dye laser: a randomized, doubleblind, intrapatient left-to-right study. J Am Acad Dermatol 66: $807-812$

63. Al-Mutairi N, Noor T, Al-Haddad A (2014) Single blinded left-toright comparison study of excimer laser versus pulsed dye laser for the treatment of nail psoriasis. Dermatol Ther (Heidelb) 4:197-205

64. Stern DK, Creasey AA, Quijije J, Lebwohl MG (2011) UV-A and UV-B penetration of normal human cadaveric fingernail plate. Arch Dermatol 147:439-441

65. Seebode C, Lehmann J, Emmert S (2016) Photocarcinogenesis and skin cancer prevention strategies. Anticancer Res 36(3):1371-1378

66. Holme SA, Anstey AV (2004) Phototherapy and PUVA photochemotherapy in children. Photodermatol Photoimmunol Photomed 20:69-75 